\title{
THE BUSINESS-IT RELATIONSHIP: TOWARDS A PARTNERSHIP RELATION
}

\author{
Anton Manfreda, University of Ljubljana, Faculty of Economics, anton.manfreda@ef.uni-lj.si \\ Mojca Indihar Štemberger, University of Ljubljana, Faculty of Economics, mojca.stemberger@ef.uni-lj.si
}

\begin{abstract}
The relationship between top management and IT personnel or the business-IT relationship has been the subject of research for over 50 years since the relationship between them is often inefficient and prevents the effective use of IT in the company. This inefficient relationship is often denoted as a gap between top management and IT personnel. Due to the significance that business-IT relationship has on the success of IT implementation, the purpose of this paper is to contribute to understanding the business-IT gap and to improve the cooperation between them. The survey on IT management side and top management side will enable to present factors that cause the business-IT gap and even more, to present and expose factors that lead to different form of business-IS relationship, namely a partnership relation.
\end{abstract}

Keywords: Business-IT Relationship, Business-IT Partnership, IT Personnel, Top Management and Business-IT Gap

\section{INTRODUCTION}

The relationship between IT managers and top managers has been the subject of research for many decades. In the expert literature it is usually claimed that the relationship between business and IT spheres has been problematic since the emergence of computer applications for general business use in the 1960s [11, 43]. An inefficient relationship between managers and IT personnel is often referred to in the literature as a gap or even a 'cultural' gap between the two sides $[9,15,35]$ which is generally defined as a lack of understanding between management and IT personnel in the company $[9,35]$. Merely a few companies have been able to successfully bridge the gap [35], and therefore companies are still insufficiently aware of the consequences of this inappropriate relationship.

The professional and scholar literature lacks research on how to provide sufficient conditions for establishing an efficient relationship between top managers and IT personnel. An efficient relationship indicates a special form of relationship between them, namely a partnership relationship. However, the term partnership is not researched in the scholar business-IT literature. It has been argued that the business-IT partnership is important for organisations because companies can thus concentrate on implementing IT in order to realise the business strategy [31], although there are no guidelines concerning how to achieve this partnership.

This paper thus presents a brief literature review on topics related to business-IT relationship, namely the gap between top management and IT personnel, top management support, alignment and partnership. Further it describes the methodology, preliminary results, proceeding steps in the research and gives some concluding remarks.

\section{LITERATURE REVIEW}

\section{The gap between top management and IT personnel}

Companies have become more dependent on IT in the last decades [34] and therefore the importance of the relationship between IT personnel and business personnel has grown strongly. Since that relationship is often problematic, it is referred to in the literature as a gap between the two sides $[9,15,35]$.

The gap is defined as a lack of understanding between the management side and the IT side in the company [9, 35]. Further, the gap generally represents the problematic relationship between the business and IT spheres as a consequence of the difference between them [43].

These differences mainly involve varying views concerning the role of the IT department. Top management namely often considers the IT department as a supporting function merely where automating the business processes is its 


\section{Issues in Information Systems \\ Volume 14, Issue 2, pp.359-366, 2013}

sole purpose [13]. Thus, IT is mainly viewed in companies as a cost, which consequently even worsens the relationship between top management and IT personnel.

The gap therefore causes different views and expectations from IT personnel and top management and hence prevents organisations from developing competitive advantages arising from IT [15, 43]. Despite several attempts to reduce the gap, business departments and IT departments in many companies still do not share identical views regarding the role of IT personnel [30]. Although several studies confirm that the business-IT relationship is poor in many companies, there is still hardly any guidance on how to bridge the gap [34].

The presence of the gap in the business-IT alignment has also been reported in the public sector [2] where it has been found that an alignment gap exists between business and IT strategies according to four criteria, namely: management and leadership, applied systems and electronic services, technical infrastructure, and human resources. It was also found in in-depth interviews with IT managers in [1] that leadership, processes, service quality and values are the most important factors representing the cultural gap between the IT strategy, yet there is no empirical evidence presenting the reasons for the gap.

\section{Top management support}

Top management support is thus one of the most important factors for successful IT initiatives [21]. It has even been claimed that top management support is the most important success factor for successful IT projects [45].

Top management support is defined mainly as supporting initiatives of IT personnel and participating in IT implementation projects [36]. On the contrary, a lack of top management support in the company causes resources to be allocated to other projects that are perceived as important by top management [24]. Consequently, it causes unsuccessful IT activities and a resistance to IT implementation [29]. Top management is therefore even less willing to cooperate with IT personnel, which further worsens the relationship between them [30].

Several empirical studies confirm that top management support also has an impact on the success of IT implementation $[5,36]$. It has also been shown that top management support particularly contributes to an increase in IS project performance [33].

It has been shown that managerial and business knowledge and skills are crucial for obtaining top management support [20]. However, obtaining that support is not merely a domain of IT personnel. It is also important that top management understands the strategic role of IT personnel and provides enough resources for IT project implementation [37].

Responsible top management thus has an important role as simply considering the strategic role of IT and its integration into business processes leads to comparative advantages, while technology itself is not a sufficient factor of successful IT implementation [10]. However, it is the IT manager's role to present IT as a strategic resource delivering a value to the organisation [14]. Therefore, it seems that having a top management support is not a sufficient condition to fully use IT as a competitive advantage. Thus, a special relationship term should be presented, namely partnership relation.

\section{Business-IT alignment}

Business-IT alignment is generally claimed as applying IT in an appropriate and timely way in harmony with the business strategies, goals and needs [26] and has been one of the most important concerns of business and IT executives and IT practitioners for almost two decades [27]. Business-IT alignment is claimed to be important for companies since it enables a company to maximise its IT investments and achieve consonance with its business strategies and plans, and consequently greater profitability. It namely eases the development and implementation of efficient IT strategies, thus enabling that company to focus on the IT implementation to improve the business [31].

Henderson and Venkatraman [18] were some of the first to present the relations between business strategies and IT in a model. Strategic fit indicates that any strategy has to deal with external and internal domains. The model represents the capability of IT to support the business strategy and the link between organisational infrastructure and processes. The model is widely used in the business-IT alignment theories [8] since it shows that in order to become a successful company the IT strategy should be fully aligned with the business strategy. The model has also been 


\section{Issues in Information Systems \\ Volume 14, Issue 2, pp.359-366, 2013}

empirically tested with several companies that successfully used it to assess their level of alignment $[12,32]$ and was also extended by providing practical ways to achieve alignment [3].

Strategic alignment presented a new view on IT and its role in the development of business strategies [31] since it deals with both strategy and infrastructure concerns to achieve business-IT alignment. Further, it has been shown that strategic alignment has a positive influence on managing enterprise resource planning projects and enabling faster reaction times to business events [42].

However, a recent study has shown that mutual understanding between top management and IT managers regarding the role of IT leads to an IT strategic alignment [22] and therefore, denoted the existence of additional factors in the business-IT relationship that may present a different form of relationship or deviation from alignment towards partnership.

\section{Business-IT partnership}

The term partnership generally describes the relations between companies or organisations. It has been claimed that companies should establish partnerships to create top products, attract valuable customers and increase profits [40].

Nevertheless, there have been some attempts to define the term partnership also in the business-IT context where it refers to the organisational ability to join cross-functional efforts in positioning IT to support and form business opportunities [41]. It has also been claimed that partnership relation is the most important factor for successful IT implementation.

Some measures for the business-IT partnership were developed in the study [38] examining the influence of IS resources and capabilities on the organisational performance. The term partnership was also used in the study, claiming that the business-IT partnership is important for organisations since, by understanding it, organisations can concentrate on implementing the IT in order to enable the business strategy [31]; however the research showed no suggestions on how to achieve this partnership.

Moreover, the relationship between alignment and partnership was mentioned in the research claiming that alignment results in a partnership between IT managers and top executives in developing and achieving their strategies and goals [6] where partnership in this research related to the mutually perceived contribution of IT and business. However, the research focused more on the partnership maturity rather than business-IT partnership. Variables measuring partnership maturity in that research were based on the strategic alignment model $[25,39]$.

The term partnership related to business-IT context was also used in the research expressing principles of good IT governance [7] since it has been claimed that exemplary IT governance is an organisational partnership between business and IT where both sides have decision rights and accountabilities. However, the research did not present any factors that are leading to the partnership relations or any factors measuring it.

Several items among others from the presented studies were included in measuring partnership relation in this research, namely top management believes that IT personnel will perform their obligations in a quality way, further communication between top management and IT personnel is open, and lastly IT manager is involved in formulating business strategies.

Based on the research examining the relationships between non-governmental development organisations [28] additional items were included to measure the partnership relation like top management can rely upon IT personnel and that mutual reliance exists between them.

\section{RESEARCH METHODOLOGY}

The empirical research was done on medium and large Slovenian companies. The entry condition for including a company in the research is that it had to satisfy at least two of the criteria, namely (1) to have at least 50 employees, (2) to have a net turnover exceeding EUR 8,800,000 and (3) to have an asset value exceeding EUR 4,400,000. Consequently, 1,495 companies were suitable to participate in the research. All these companies were contacted by telephone and their IT managers were invited to participate in the research. Companies where no one was formally involved in IT were excluded from the research. At the same time, also top managers were invited to participate in 


\section{Issues in Information Systems \\ Volume 14, Issue 2, pp.359-366, 2013}

the research. From the total 1,495 eligible companies, 450 top managers were randomly selected and invited to participate in the study. Altogether, 221 IT managers and 93 top managers finally participated in the survey; and thus, 314 cases suitable for the analysis were obtained.

Two questionnaires were therefore developed, namely for IT managers and for top management. The questionnaire for top management was in online form only, while the questionnaire for IT managers was in online and printed from, and therefore IT managers participated in an online survey or in the form of structured interviews. Both questionnaires were, beside some general questions, composed of 10 items measuring the importance and position of IT personnel, 11 items measuring the partnership relation, 16 items measuring the importance of different skills and knowledge for IT managers; and 13 items measuring the role of IT personnel. The questionnaire for IT managers had an additional 16 items measuring the quality of the knowledge and skills possessed by the individual IT managers who participated in the research.

The items used in the research were measured with 7-point Likert scales. Both questionnaires were built on the basis of different findings in the literature [4, 44] and previous research [16, 20], while some items (the importance of knowledge and skills) were structured more into detail.

\section{PRELIMINARY RESULTS}

Preliminary results of exploratory factor analysis using a principal axis factoring extraction method with a Varimax rotation are indicating several important factors in the business-IT relationship. Below, the Scree Plot is presented showing the relative importance of each factor. Based on the Scree Plot seven factors were decided to be included in the further analysis. These seven factors explain almost $66 \%$ of total variance. The last factor included in the analysis, namely the seventh factors adds additional $3.1 \%$ to the total variance, while the first factor explains $26.4 \%$ of the total variance.

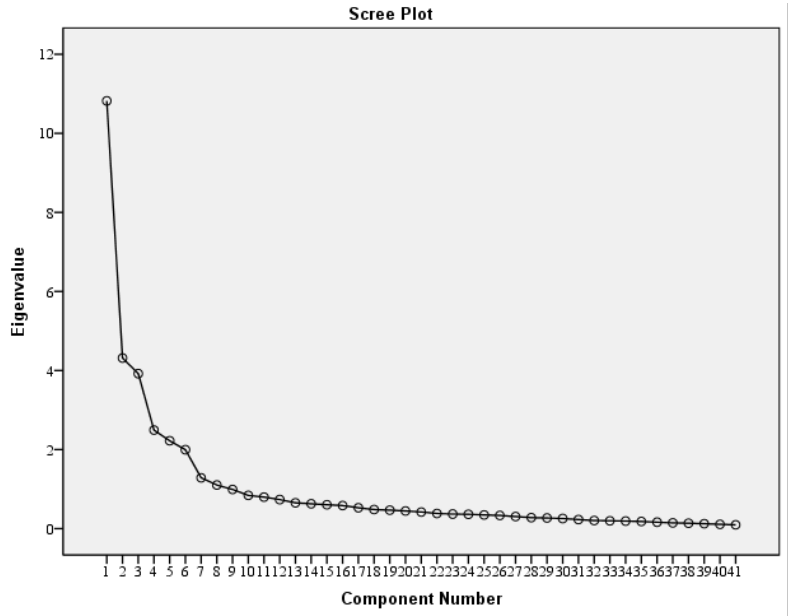

Figure 1. Scree Plot

Tables 1 and 2 present the factor loadings for the predefined variables. The factor loadings are divided into two tables merely due to its size and thus to ease a factor representation. All items were subject of data analysis (data reduction) at the same time.

According to the guidelines for identifying significant factor loadings, the limit of 0.40 is generally appropriate for a sample size larger than 200. However, values larger than 0.50 are desired to guarantee practical significance as well [17]. Accordingly, in both tables, items with factor loading larger than 0.5 are used to represent a specific factor and bolded for easier representation. 


\section{Issues in Information Systems}

Volume 14, Issue 2, pp.359-366, 2013

Table 1. Factor loadings - part 1

\begin{tabular}{|l|c|c|c|c|c|c|c|}
\hline \multirow{2}{*}{ Item description } & \multicolumn{7}{|c|}{ Factor $($ KMO $=\mathbf{0 . 8 6 7})$} \\
\cline { 2 - 7 } & $\mathbf{1}$ & $\mathbf{2}$ & $\mathbf{3}$ & $\mathbf{4}$ & $\mathbf{5}$ & $\mathbf{6}$ & 7 \\
\hline Independent IT personnel & $\mathbf{. 6 1 2}$ & .119 & .027 & .195 & -.005 & -.008 & .195 \\
\hline Top management relies on IT personnel & $\mathbf{. 5 1 2}$ & -.020 & -.018 & .415 & -.176 & .070 & .283 \\
\hline Top management respects the work of IT personnel & $\mathbf{. 8 6 1}$ & .212 & .036 & -.003 & .109 & .099 & .065 \\
\hline $\begin{array}{l}\text { Trusting IT personnel to perform obligations } \\
\text { in a quality way }\end{array}$ & $\mathbf{. 8 1 1}$ & .012 & .043 & .186 & -.085 & .107 & .101 \\
\hline Mutual reliance & $\mathbf{. 8 7 3}$ & .102 & .069 & .069 & -.041 & .113 & .106 \\
\hline Involvement in the company's development & $\mathbf{. 7 4 5}$ & .264 & .151 & .200 & -.044 & -.090 & -.051 \\
\hline Aligned objectives & $\mathbf{. 6 0 6}$ & .234 & .212 & .293 & -.065 & -.023 & -.034 \\
\hline Long-term cooperation & $\mathbf{. 8 2 5}$ & -.036 & .049 & .144 & -.061 & .036 & .031 \\
\hline Commitment to a good relationship & $\mathbf{. 8 6 3}$ & .151 & .072 & -.030 & .043 & .056 & -.022 \\
\hline Open and honest communication & $\mathbf{. 8 3 9}$ & .101 & .138 & -.018 & -.038 & .098 & .037 \\
\hline Involvement in formulating business strategies & $\mathbf{. 6 4 0}$ & .313 & .182 & .062 & -.036 & -.216 & -.059 \\
\hline Identifying IS needs & -.029 & $\mathbf{. 5 9 2}$ & .111 & .181 & .050 & .247 & .156 \\
\hline Formulating IS architecture & -.075 & $\mathbf{. 6 4 2}$ & .009 & .020 & .177 & .285 & -.020 \\
\hline On-time concluding IS projects & .231 & $\mathbf{. 7 6 9}$ & .127 & .007 & -.059 & .012 & .104 \\
\hline Proper IS organisation & .152 & $\mathbf{. 6 9 2}$ & .059 & .055 & -.007 & .369 & .077 \\
\hline Implementing projects in a cost-specified range & .236 & $\mathbf{. 6 9 7}$ & .059 & .104 & .031 & .124 & .101 \\
\hline Improving and redesigning business processes & .152 & $\mathbf{. 5 8 1}$ & .143 & .159 & .087 & -.027 & .238 \\
\hline Strategic IS planning & .282 & $\mathbf{. 7 4 8}$ & .114 & .150 & .013 & -.045 & .051 \\
\hline Controlling the performance of IS projects & .209 & $\mathbf{. 8 2 6}$ & .156 & .086 & -.055 & .106 & .041 \\
\hline Planning and organising & .034 & .155 & $\mathbf{. 8 1 0}$ & .109 & -.018 & .066 & .057 \\
\hline Motivation & .091 & .053 & $\mathbf{. 7 6 8}$ & .159 & -.114 & .121 & .156 \\
\hline Project management & .142 & .090 & $\mathbf{. 8 0 2}$ & .124 & -.062 & .021 & .131 \\
\hline Team-working & .066 & .207 & $\mathbf{. 7 6 8}$ & .118 & .066 & .020 & .145 \\
\hline Communication and coordination & .130 & .086 & $\mathbf{. 8 0 1}$ & .044 & -.194 & .114 & .231 \\
\hline Knowing business processes & .271 & .050 & $\mathbf{. 5 9 7}$ & .042 & -.057 & -.009 & .349 \\
\hline
\end{tabular}

The value of the calculated $\mathrm{KMO}$ is above 0.8 indicating a reliable factor analysis. Values greater than 0.5 are namely acceptable [23], while values greater than 0.8 are claimed as very good [19].

From the Table 1 three factors are evident. Factor 1 consists of several variables measuring the theoretically specified partnership relation, and therefore may represent the business-IT partnership. Factor 2 is composed of several business activities of IT personnel, and thus represents the business role of the IT department, while Factor 3 includes managerial skills such as planning, motivation etc. and therefore represents managerial knowledge and skills.

From the Table 2 four factors are evident. Factor 4 includes possible effects of IT, and thus represents the importance of IT. Factor 5 is composed of items measuring technological knowledge such as programming, databases etc. and thus represents technological knowledge and skills. Factor 6 represents the technological and supportive role of the IT department since it includes items like providing user support and establishing appropriate IT infrastructure. Lastly, Factor 7 represents business knowledge and skills since it is composed of items that are related to risk management, relevant legislation etc. 


\section{Issues in Information Systems \\ Volume 14, Issue 2, pp.359-366, 2013}

Table 2. Factor loadings - part 2
\begin{tabular}{|l|c|c|c|c|c|c|c|}
\hline \multicolumn{1}{|c}{ Item description } & \multicolumn{7}{c|}{ Factor } \\
\cline { 2 - 8 } & $\mathbf{1}$ & $\mathbf{2}$ & $\mathbf{3}$ & $\mathbf{4}$ & $\mathbf{5}$ & $\mathbf{6}$ & $\mathbf{7}$ \\
\hline Enabling quality services & .326 & .151 & .170 & $\mathbf{. 7 0 4}$ & .014 & .100 & .037 \\
\hline Enabling operations with lower costs & .128 & .106 & .102 & $\mathbf{. 7 6 0}$ & .064 & .082 & .088 \\
\hline Enabling successful business performance & .128 & .115 & .166 & $\mathbf{. 8 2 6}$ & -.060 & -.008 & .031 \\
\hline Enabling competitive advantage & .149 & .195 & .103 & $\mathbf{. 8 3 1}$ & -.027 & .028 & .143 \\
\hline Programming & -.021 & .181 & -.196 & -.112 & $\mathbf{. 7 3 4}$ & .112 & .064 \\
\hline Operating systems & -.055 & .060 & -.120 & -.041 & $\mathbf{. 8 4 4}$ & .130 & -.009 \\
\hline Databases & -.008 & .046 & -.078 & .077 & $\mathbf{. 9 0 9}$ & .036 & .015 \\
\hline Telecommunications and networks & -.076 & -.110 & .069 & .025 & $\mathbf{. 8 1 3}$ & .040 & .084 \\
\hline Establishing the appropriate infrastructure & .021 & .121 & .023 & .030 & .152 & $\mathbf{. 8 6 1}$ & -.031 \\
\hline Providing user support & .130 & .155 & .212 & .016 & .091 & $\mathbf{. 7 7 6}$ & -.050 \\
\hline Concern for IS security & -.025 & .265 & -.017 & .030 & .083 & $\mathbf{. 8 1 4}$ & .017 \\
\hline Cooperating with external suppliers & .109 & .123 & .098 & .157 & -.014 & $\mathbf{. 5 5 4}$ & .219 \\
\hline Knowing relevant legislation & .095 & .031 & .279 & -.011 & .147 & .102 & $\mathbf{. 6 9 9}$ \\
\hline Risk management & .098 & .164 & .445 & .022 & -.148 & .017 & $\mathbf{. 6 0 3}$ \\
\hline Knowing individual functional areas & .037 & .206 & .182 & .177 & .118 & .094 & $\mathbf{. 7 0 0}$ \\
\hline Knowing business competitors & .055 & .226 & .241 & .164 & .029 & -.180 & $\mathbf{. 6 5 4}$ \\
\hline
\end{tabular}

FUTURE RESEARCH

The research in progress is consisted of interviews with IT managers and top management in medium and large enterprises in Slovenia. The purpose of developing two surveys is to present the differences in views between top managers and IT personnel since it allows a comparison of the responses of top management with the responses of IT managers or persons responsible for IT. This in fact also enables the factors that are causing the gap between top management and IT personnel to be identified, as well as the factors that lead to greater cooperation between them.

The comparison of two questionnaires will enable to reveal the most important factors that increase the gap between IT personnel and top management. Further, the research will also present factors that lead to the partnership relation between them.

Comparing means method will be used to present key differences between IT personnel and top management, while structural equation modelling will be used to present a possible approach to achieve partnership relation.

\section{CONCLUSIONS}

The business-IT gap remains an important issue since it influences the success of IT implementation and consequently the company overall performance. The purpose of this research is not to eliminate the gap because differences between the business side and IT side will always exist. Instead, the purpose is to enhance understanding of the gap between business and IT personnel and to reduce the gap by creating a partnership between them. The research will thus identify the factors that are important in the business-IT relationship and factors leading to business-IT partnership.

Defining the gap is particularly important because misunderstanding between top management and IT personnel can be removed to some extent by knowing the factors important in this relationship and knowing particular fields within these factors where significant differences exist. Although this gap will probably always exist, the findings of this research will allow that the gap will be reduced and better understandable. 


\section{Issues in Information Systems \\ Volume 14, Issue 2, pp.359-366, 2013}

\section{REFERENCES}

1. Al Majali, D., \& Dahlin, Z. (2010). Diagnosing the gap in IT - business strategic alignment: a qualitative analysis among public shareholding firms in Jordan. International Journal of Electronic Business Management, 8(4), 263-271.

2. Atafar, A., Akbari, N., \& Bidmeshk, O. (2011). Determining the Strategic Alignment Between IT Strategies and Business Strategies In Esfahan Municipality. Interdisciplinary Journal of Contemporary Research In Business, 3(6), 302-310.

3. Avison, D., Jones, J., Powell, P., \& Wilson, D. (2004). Using and validating the strategic alignment model. The Journal of Strategic Information Systems, 13(3), 223-246.

4. Byrd, T. A., \& Davidson, N. W. (2003). Examining possible antecedents of IT impact on the supply chain and its effect on firm performance. Information \& Management, 41(2), 243-255.

5. Caldeira, M. M., \& Ward, J. M. (2002). Understanding the successful adoption and use of IS/IT in SMEs: an explanation from Portuguese manufacturing industries. Information Systems Journal, 12(2), 121-152.

6. Chen, L. (2010). Business-IT alignment maturity of companies in China. Information \& Management, 47(1), 9-16.

7. Chris, G. (2005). IT governance - are boards and business executives interested onlookers or committed participants? Australian Accounting Review, 15(3), 5-10.

8. Coleman, P., \& Papp, R. (2006). Strategic alignment: analysis of perspectives. Paper presented at the Southern Association for Information Systems Conference.

9. Coughlan, J., Lycett, M., \& Macredie, R. D. (2005). Understanding the business-IT relationship. International Journal of Information Management, 25(4), 303-319.

10. Dhillon, G. (2008). Organizational competence for harnessing IT: A case study. Information \& Management, 45(5), 297-303.

11. Doll, W. J., \& Ahmed, M. U. (1983). Diagnosing and Treating the Credibility Syndrome. MIS Quarterly, 7(3), 21-32.

12. Dong, X., Liu, Q., \& Yin, D. (2008). Business Performance, Business Strategy, and Information System Strategic Alignment: An Empirical Study on Chinese Firms. Tsinghua Science \& Technology, 13(3), $348-354$.

13. Dos Santos, B., \& Sussman, L. (2000). Improving the return on IT investment: the productivity paradox. International Journal of Information Management, 20(6), 429-440.

14. Earl, M. J., \& Feeney, D. F. (1994). Is Your CIO Adding Value? Sloan Management Review, 35(3), 11-20.

15. Grindley, K. (1992). Information systems issues facing senior executives: the culture gap. The Journal of Strategic Information Systems, 1(2), 57-62.

16. Groznik, A., Kovačič, A., Jaklič, J., \& Indihar Štemberger, M. (2001). A comparison of the strategic IS planning practices in the developed and transition countries. Journal of information technology management, 11(1-2), 25-44.

17. Hair, J. F., Anderson, R. E., Tatham, R. L., \& Black, W. C. (1998). Multivariate Data Analysis (5th ed.). New Jersey: Prentice-Hall.

18. Henderson, J. C., \& Venkatraman, N. (1993). Strategic alignment: Leveraging information technology for transforming organizations. IBM Systems Journal, 32(1), 4-17.

19. Hutcheson, G., \& Sofroniou, N. (1999). The multivariate scientist. London: Sage Publications.

20. Indihar Štemberger, M., Manfreda, A., \& Kovačič, A. (2011). Achieving top management support with business knowledge and role of IT/IS personnel. International Journal of Information Management, 31(5), 428-436.

21. Jarvenpaa, S. L., \& Ives, B. (1990). Information Technology and Corporate Strategy: A View from the Top. Information Systems Research, 1(4), 351-376.

22. Johnson, A. M., \& Lederer, A. L. (2010). CEO/CIO mutual understanding, strategic alignment, and the contribution of IS to the organization. Information \& Management, 47(3), 138-149.

23. Kaiser, H. (1974). An index of factorial simplicity. Psychometrika, 39(1), 31-36.

24. Kappelman, L. A., McKeeman, R., \& Zhang, L. (2006). Early warning signs of IT project failure: The dominant dozen. Information Systems Management, 23(4), 31-36.

25. Luftman, J. N. (2000). Assessing Business-IT Alignment Maturity. Communications of the Association for Information Systems, 4(14), 1-50.

26. Luftman, J. N. (2004). Assessing business-IT alignment maturity. In W. Van Grembergen (Ed.), Strategies for information technology governance (pp. 99-128). London: Idea Group Publishing.

27. Luftman, J. N. (2005). Key issues for IT executives 2004. MIS Quarterly, 4(2), 269-285. 


\section{Issues in Information Systems \\ Volume 14, Issue 2, pp.359-366, 2013}

28. Malena, C. (1995). Relations between northern and southern non-governmental development organizations. Canadian Journal of Development Studies, 16(1), 7-30.

29. Newman, M., \& Zhao, Y. (2008). The process of enterprise resource planning implementation and business process re-engineering: tales from two Chinese small and medium-sized enterprises. Information Systems Journal, 18(4), 405-426.

30. Nord, J. H., Nord, D. G., Cormack, S., \& Cater-Steel, A. (2007). An investigation of the effect of Information Technology (IT) culture on the relationship between IT and business professionals. International Journal of Management \& Enterprise Development, 4(3), 265-292.

31. Papp, R. (1999). Business-IT alignment: productivity paradox payoff? Industrial Management \& Data Systems, 99(8), 367-373.

32. Papp, R. (2004). Assessing Strategic Alignment in Real Time. Journal of Informatics Education Research, 6(1), 11-28.

33. Parolia, N., Goodman, S., Li, Y., \& Jiang, J. J. (2007). Mediators between coordination and IS project performance. Information \& Management, 44(7), 635-645.

34. Peppard, J. (2001). Bridging the gap between the IS organization and the rest of the business: plotting a route. Information Systems Journal, 11(3), 249-270.

35. Peppard, J., \& Ward, J. (1999). 'Mind the Gap': diagnosing the relationship between the IT organisation and the rest of the business. The Journal of Strategic Information Systems, 8(1), 29-60.

36. Ragu-Nathan, B. S., Apigian, C. H., Ragu-Nathan, T. S., \& Tu, Q. (2004). A path analytic study of the effect of top management support for information systems performance. Omega, 32(6), 459-471.

37. Ranganathan, C., \& Kannabiran, G. (2004). Effective management of information systems function: an exploratory study of Indian organizations. International Journal of Information Management, 24(3), 247-266.

38. Ravichandran, T., \& Lertwongsatien, C. (2005). Effect of Information System Resources and Capabilities on Firm Performance: A Resource-Based Perspective. Journal of Management Information Systems, 21(4), 237276.

39. Sledgianowski, D., Luftman, J. N., \& Reilly, R. R. (2006). Development and validation of an instrument to measure maturity of IT business strategic alignment mechanisms. Innovative Technologies for Information Resources Management, 19(3), 18-33.

40. Teng, B. S. (2003). Collaborative advantage of strategic alliances: value creation in the value net. Journal of General Management, 29(2), 1-22.

41. Tian, J., Wang, K., Chen, Y., \& Johansson, B. (2010). From IT deployment capabilities to competitive advantage: An exploratory study in China. Information Systems Frontiers, 12(3), 239-255.

42. Velcu, O. (2010). Strategic alignment of ERP implementation stages: An empirical investigation. Information \& Management, 47(3), 158-166.

43. Ward, J., \& Peppard, J. (1996). Reconciling the IT/business relationship: a troubled marriage in need of guidance. The Journal of Strategic Information Systems, 5(1), 37-65.

44. Ward, M. A., \& Mitchell, S. (2004). A comparison of the strategic priorities of public and private sector information resource management executives. Government Information Quarterly, 21(3), 284-304.

45. Young, R., \& Jordan, E. (2008). Top management support: Mantra or necessity? International Journal of Project Management, 26(7), 713-725. 